\title{
ACTIVISMO BARRIAL DE JÓVENES ORGANIZADOS: ALGUNAS CARACTERÍSTICAS DE LA MILITANCIA TERRITORIAL EN LOS BARRIOS GRAN BUENOS AIRES ${ }^{1}$.
}

\author{
NEIGHBORHOOD ACTIVISM OF ORGANIZED YOUTH: SOME \\ CHARACTERISTICS OF THE MILITANCE IN BUENOS AIRES \\ METROPOLITAN AREA ${ }^{2}$
}

\section{Melina Vázquez ${ }^{3}$}

\section{y Pablo Vommaro ${ }^{4}$}

Palabras clave: jóvenes, política, activismo, territorio, movimientos sociales, Argentina

Keywords: young people, politics, activism, territory, social movements, Argentina

\section{Resumen}

Este artículo estudia las prácticas políticas de las y los jóvenes organizados en los barrios populares del Gran Buenos Aires. A partir de la identificación de seis ejes se realiza una caracterización de las prácticas políticas impulsadas por una generación de jóvenes, socializada en el marco de la profundización de las políticas neoliberales y de la deslegitimación de la política institucional. De esta manera, se busca aportar a la comprensión de los colectivos y redes sociales que estos jóvenes conforman mostrando, por un lado, cómo el territorio se convierte en un ámbito central de la organización social, política y de la vida cotidiana. Por otro, recuperando la noción de autonomía, entendida como forma de construcción política independiente y, al mismo tiempo, confrontativa con el Estado, que da sentido a la acción directa organizada desde abajo.

\section{Abstract:}

This paper shows the political practices of young people organized in popular neighborhoods of Buenos Aires Metropolitan Área, Argentina. Based on the
Páginas 135 - 156

1 El presente artículo es parte de los resultados parciales de las investigaciones de las tesis doctorales de los autores. Las mismas fueron financiadas por el Consejo Nacional de Investigaciones Científicas y Tecnológicas (CONICET). Además, el artículo forma parte del trabajo que desarrollan los autores, tanto en el Grupo de Trabajo CLACSO "Juventud y nuevas prácticas políticas en América Latina" como también en el proyecto UBACyT "Nuevas subjetividades políticas en la Argentina. Un estudio comparado de las organizaciones piqueteras a partir de la crisis de 2001" (2004-2007), dirigido por Federico Schuster. El mismo se inscribe en el Grupo de Estudios sobre Protesta Social y Acción Colectiva, Instituto de Investigaciones Gino Germani, Universidad de Buenos Aires, Argentina. Una versión preliminar de este texto fue presentada en la mesa "Juventud y participación política en Argentina y en América Latina. Formas de compromiso político, militancia y movilización social de los jóvenes entre la década del ` 60 y la actualidad", coordinada por los autores, y realizada en las XII Jornadas Interescuelas y/o Departamentos de Historia celebradas en octubre de 2009 en Bariloche (Argentina).

2 Traducción de Blanca Stella Giraldo Revisión Centro de Traducción del Instituto de Idiomas UAM.

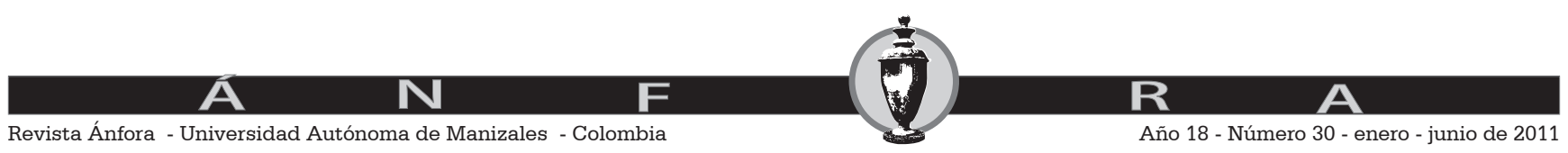


identification of six axes, a characterization of political practices driven by a generation of young people was carried out. This generation grew up within the context of the deepening of neoliberal policies and the delegitimization of the institutional policy. Thus, this paper aims at contributing to the understanding of groups and social networks, constituted by these young people showing how the territory became a central area of the social, political and daily life, on one hand. On the other hand, it shows the recovery of the concept of autonomy, understood as a form of independent political construction, while being confrontational with the State, which gives meaning to the direct action organized from the bottom.

\section{Introducción}

El artículo analiza algunas de las características del activismo de los y las jóvenes en los barrios populares del Gran Buenos Aires. El propósito es sistematizarlas para dar cuenta de los cambios más significativos que se produjeron en los últimos años, tanto en el activismo juvenil, como también en las formas de hacer política que tienen como centro el trabajo barrial.

Estas cuestiones no pueden ser entendidas sin reconocer en ello una expresión de cambios más amplios y de más larga duración que nos sitúan en los inicios de la última dictadura militar en Argentina (1976-1983). En ese momento comenó a implementarse un conjunto de medidas económicas y políticas que fueron centrales para el impulso y profundización del régimen neoliberal durante la década de 1990. Además, y fundamentalmente para nuestro análisis, se profundizó un proceso de deslegitimación de la política institucional que fue traduciéndose en una creciente crisis de representación política, cuya expresión más visible fue la crisis del 19 y 20 de diciembre de 2001.

Sin embargo, la crisis de la política en el ámbito institucional no implicó un proceso de despolitización de la sociedad, sino que dio lugar a la producción de una disputa acerca de los propios límites de lo político. Este conflicto, analizado desde abajo, permite reconocer vías de reformulación de la política que, aunque no son completamente independientes de las expresiones institucionales de la misma, buscan construir modelos de politización y participación política relativamente independientes de las formas políticas clásicas -partidarias y sindicales- asociadas al Estado.

En este trabajo, nos enfocamos en el análisis de las expresiones organizativas y contestatarias impulsadas por los y las jóvenes en los barrios del Gran Buenos Aires. Sin duda, este análisis no supone que las afirmaciones del presente trabajo puedan ser generalizadas a la experiencia de todos los jóvenes. Quienes se enmarcan en la sociología de la juventud saben que más que de "juventud" siempre es preciso reconocer la existencia de "juventudes" puesto que de lo contrario corremos el riesgo de asumir la idea de que existe una juventud homogénea (Braslavsky, 1986). Estas reflexiones no son generaliza-
3 Licenciada en Sociología, Magíster en Ciencias Sociales y candidata a doctora por la Universidad de Buenos Aires. Es docente de la carrera de sociología y del Ciclo Básico Común de la Universidad de Buenos Aires, integrante del Grupo de Estudios de Protesta Social y Acción Colectiva (Instituto de Investigaciones Gino Germani, Universidad de Buenos Aires) y del Grupo de Trabajo CLACSO "Juventud y prácticas políticas". Correo electrónico: vazquezmelina@hotmail.com.

4 Profesor de Historia de la Universidad de Buenos Aires y doctorado en Ciencias Sociales, Facultad de Ciencias Sociales, Universidad de Buenos Aires. Investigador del Grupo de Estudios de Protesta Social y Acción Colectiva (GEPSAC, Instituto de Investigaciones Gino Germani, Universidad de Buenos Aires). Co-coordinador del Grupo de Trabajo "Juventud y nuevas prácticas políticas en América Latina", junto a Sara V. Alvarado, Consejo Latinoamericano de Ciencias Sociales (CLACSO). Becario del CONICET e investigador del Programa de Historia Oral de la Facultad de Filosofía y Letras, UBA, y de la Fundación de Investigaciones Sociales y Políticas (FISyP). Docente e investigador de la Universidad de Buenos Aires. Correo electrónico: pvommaro@gmail.com.

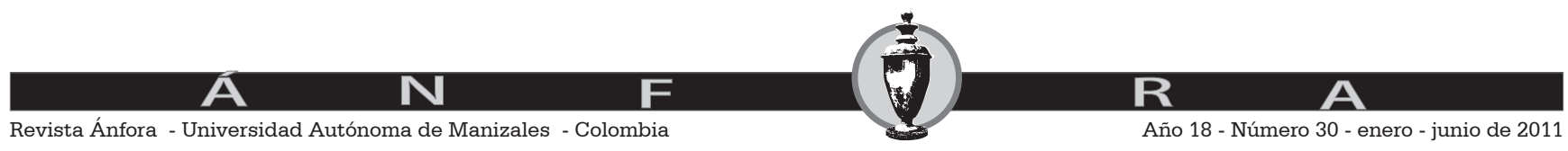


bles, por un lado, porque se centran exclusivamente en la experiencia de jóvenes que participan políticamente en un conjunto de espacios que, aunque sean diferentes entre sí, comparten el hecho de reconocer su práctica como una práctica política. Por otro lado, porque las particularidades de los cambios sobre los que hacemos referencia desaconsejan ver en los resultados de este trabajo una sistematización de las experiencias de los jóvenes organizados de toda la Argentina. Las transformaciones más importantes en cuanto a la territorialización de la política, por ejemplo, permiten acotar las explicaciones no sólo a los barrios del Gran Buenos Aires, sino fundamentalmente a aquellos ubicados en la zona sur de la región. Este fue uno de los polos de mayor conflictividad social en las últimas décadas y también allí se constituyó una densa red de organizaciones que podemos caracterizar como territoriales.

Finalmente, el trabajo no incluye la experiencia de activismo de jóvenes en partidos políticos, sindicatos, ni en marcos institucionales clásicos de la política. Se trata de una reflexión sobre los y las jóvenes que se inscriben en espacios autodefinidos como autónomos y que tienen como horizonte la construcción de modalidades alternativas de la práctica política.

\section{Cambios en la política durante los años del neoliberalismo en Argentina}

Para desentrañar los significados de la política en los barrios populares del conurbano bonaerense, es preciso analizar algunas de las transformaciones de la misma que se han producido en la década del noventa. En esta ponencia nos focalizamos en la denominada "territorialización de la política" (Merklen 2004 y 2005, Frederic 2004, Delamata 2004), a través de la cual analizaremos los significados y las representaciones sobre la política de las y los jóvenes organizados en los barrios populares del GBA.

Con la transición a la democracia en la Argentina se presentó el desafío de repensar y resituar la política enmarcada institucionalmente. Durante décadas, la sucesión entre gobiernos democráticos y golpes de Estado, hizo que la política fuera disociada de la legitimidad de las instituciones y los mecanismos democráticos de toma de decisiones y de elección de representantes. En efecto, durante las décadas del sesenta y del setenta no sólo se fueron modificando los márgenes de la política sino que, además, está dejó de estar vinculada con las instituciones liberales y fue asociada, cada vez más, con proyectos emancipadores de diverso tipo, que coincidían en reconocer en la política el puente o la vía hacia la revolución social.

La derrota de dichos proyectos, consumada por parte de las fuerzas ilegales, no sólo se manifestó en la represión abierta y la desaparición de toda una generación de militantes sino que, además, buscó obturar todo tipo de manifestación y organización colectiva. Aún así, no fueron pocas las experiencias que lograron gestarse en las grietas del autodenominado Proceso de

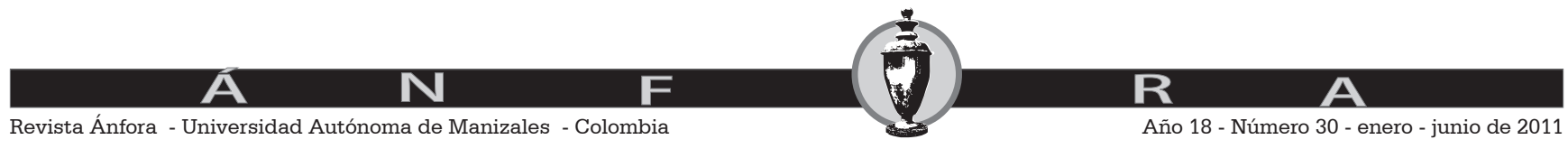


Reorganización Nacional. Como sostiene Elizabeth Jelin (1985) "La propuesta gubernamental era la búsqueda del orden y la disciplina a través de la privatización e individuación (...) no más actores colectivos, acciones colectivas, identidades grupales. Durante un tiempo, esto funcionó con bastante éxito y eficacia. (...) Pero después, poco a poco, el panorama fue cambiando. Primero las Madres en la plaza [de Mayo] y la posterior ampliación del movimiento de derechos humanos, los jóvenes en los conciertos de rock, tímidas acciones colectivas en barrios obreros y villas, alguna manifestación de mujeres, una que otra protesta que trasciende la fábrica o lugar de trabajo" (1985:16).

Cabe remarcar que en el período 1976-1983 ni el movimiento estudiantil ni los partidos eran capaces de canalizar el activismo de los jóvenes. Además, "ser joven" era un signo de "peligrosidad" para la dictadura militar, lo cual se evidencia en que la mayoría de los desaparecidos eran personas jóvenes 5 . De ahí que los espacios de inscripción de estos últimos combinaran lo político con lo estético, formas de resistencia cultural en las que aspectos expresivos y simbólicos se convertían en materia prima para la creación de estrategias colectivas de resistencia y de formación de identidades colectivas. Así, vemos la importancia que tuvo, por ejemplo, la música. Más específicamente el rock nacional, como vía de expresión de la oposición al régimen y de construcción ideológica y simbólica de nuevos valores y formas de comportamiento.

La vuelta de la democracia en 1983 abrió múltiples expectativas en cuanto a la posibilidad de retornar a un Estado de derecho que permitiera poner fin a la brutal represión y, como sostiene Merklen (2005), constituyó una oportunidad para "restituir la política en su lugar". Fue así como se definieron los contornos de la "buena política", cuyo actor principal era el ciudadano, el acto político por excelencia la participación electoral a través del voto y la representación sería articulada a partir de los partidos políticos.

Esto es lo que permite comprender la intensa participación política en partidos durante los primeros años de la democracia. Fueron especialmente los jóvenes aquellos que más compromiso mostraron en cuanto a las formas democráticas de participación. Por un tiempo, entonces, para muchos jóvenes la política podía ser entendida como sinónimo de participación en las instancias de una democracia representativa (Sidicaro, 1998).

Sin embargo, la idea de que la democracia pondría "la política en su lugar", mostró rápidamente sus limitaciones. Esto se evidenció en el "abismo creciente entre las opiniones e intereses de las personas y las instituciones políticas, la muy baja estima en que se tenía a los políticos y la política, y en especial a los procedimientos partidarios para seleccionar candidatos y tomar decisiones y a cierta sensación general de que las expectativas depositadas en los representantes habían sido, y volverían a ser una y otra vez, defraudadas" (Novaro, 1995: 96).

Nos proponemos trabajar sobre algunas de las causas por las que en la era neoliberal se gestaron modalidades de compromiso y de participación políti-
5 Según la investigadora Inés Izaguirre, un $74 \%$ de los desaparecidos eran menores de 30 años (Izaguirre, 1992). Para ampliar, consultar también el libro Nunca Más, Buenos Aires: Eudeba.

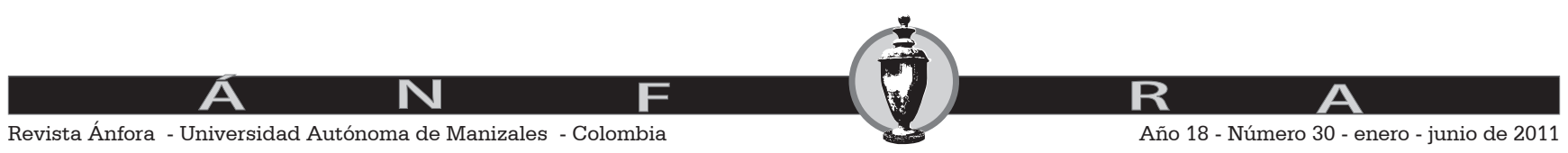


ca por fuera y en directo cuestionamiento de las vías institucionales. Es decir, que mostraron los límites del concepto de ciudadanía como única forma de implicación en la vida pública (Merklen, 2005).

La política fue progresivamente desterrada a partir de la agitación permanente de la idea de "crisis". Frente a los procesos hiperinflacionarios y los estallidos sociales que tuvieron lugar en la etapa final del gobierno de Raúl Alfonsín (1983-1989), se instaló en el discurso público un conjunto de medidas y orientaciones que aparecían como única vía de salvación nacional (Aboy Carles, 2001). Este discurso -neoliberal- pregonaba que era la intervención estatal, en todas sus expresiones, la principal causa de "la crisis". De ahí la instauración, a lo largo de la gestión Menemista (1989-1999), de un tipo de discurso y de práctica que alentaba la despolitización de la economía en función de construir un Estado mínimo y una economía fuerte de mercado.

Fue así como se comenzó a dar por tierra con un conjunto de avances en materia de derechos que habían sido bandera del peronismo durante cuarenta años. La centralidad del Estado como agente de la regulación económica, la redistribución del ingreso y la garantía de derechos laborales que habían convertido al sindicalismo en un actor corporativo de peso en la política nacional, fueron erosionados uno a uno. El gobierno de Menem era favorable a la idea de racionalizar y achicar el Estado, de ahí el tipo de políticas que impulsó, como la reducción del gasto público, las leyes de Reforma del Estado y de Emergencia Económica (que habilitaron las privatizaciones, despidos y ajustes) y la descentralización del Estado a partir de la transferencia de funciones del plano nacional al provincial.

Siguiendo a Frederic (2003) "esta vez el problema no era la 'falta de política', como durante la transición democrática luego del último gobierno de facto (...), sino un 'exceso de política' en la vida económica (...). Las reformas neoliberales de Menem atacarían el corazón de las políticas de intervención del Estado consolidadas en su mayoría durante el primer gobierno de Perón en 1945 (...). Así, el 'giro' de Menem (...) desafió las concepciones que habían dominado el pensamiento político y económico argentino del último medio siglo, las clasificaciones sociales y políticas existentes hasta entonces y, fundamentalmente, las prácticas que sustentaban esas concepciones". (2003:62).

El modelo mercado-céntrico que instaló en la Argentina el neoliberalismo, consagraba la figura del "técnico" y el "experto" en paralelo a la desvalorización de los políticos frente a aquellos lo cual tuvo severas consecuencias para la política.

El debilitamiento del núcleo de sentido del peronismo se produjo, además, a partir del resquebrajamiento de los sindicatos y del lugar que históricamente habían ocupado como base del movimiento peronista. Esto se reflejó en la disminución del poder sindical, de sus capacidades de movilización y confrontación como en las divisiones en su interior. Como se observa en la base de protestas realizada por el Grupo de Estudios de Protesta Social y Acción Colectiva (2006), la participación de las organizaciones sindicales entre 1989

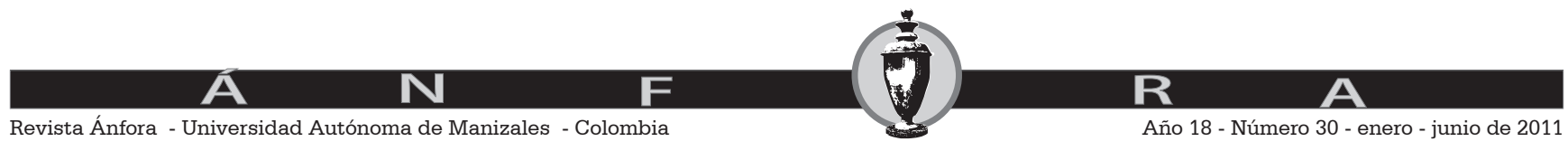


y 2003 muestra la pérdida progresiva de peso en términos absolutos y relativos de este actor en el escenario de la protesta social. Esto permite reconocer cómo se produce la desconexión entre la movilización y los actores clásicos del sistema político vinculados a la representación de intereses ${ }^{6}$.

Si durante muchos años la extensión de la condición salarial en la Argentina permitió analizar de manera paralela las transformaciones de los sectores populares urbanos con las del sindicalismo, y éste a partir de los cambios en el peronismo, desde la década del setenta esta relación comienza a deshacerse. La "paradoja de los noventa" consiste, precisamente, en el hecho de que se produce una hegemonía política por parte del Partido Justicialista al mismo tiempo que se produce el momento de máxima añoranza por parte de los sectores populares de aquellas políticas sociales integradoras que lo habían caracterizado décadas atrás. Así fue posible profundizar un modelo económico excluyente con una fuerte legitimidad política que tuvo como soporte la existencia de una cultura política vinculada al peronismo (Svampa y Pereyra, 2003).

Las transformaciones del peronismo y su persistencia en los sectores populares se hicieron evidentes a partir de, por un lado, estrategias de intervención gestadas desde redes informales barriales y el impulso de relaciones clientelares ancladas territorialmente y basadas en un intercambio desigual de "favores por votos". Sin embargo, estos aspectos "utilitarios" se fueron combinando con otros afectivos que "remiten menos a una identidad peronista activa como estructura del sentir que a un conjunto de emociones y de lealtades históricas frente al "único partido que ha hecho algo por nosotros'" (Martucelli y Svampa, 1997 citado en Svampa y Pereyra 2003:49). Ahora bien, esto adquiere características distintivas entre las y los jóvenes, quienes lejos están de reconocer en el peronismo un imaginario de integración social, como lo hacían las generaciones anteriores. De ahí la importancia de entender cómo para las y los jóvenes de sectores populares el peronismo se configura en la relación inescindible entre Partido Justicialista y clientelismo.

Ahora bien, las mutaciones acontecidas no pueden ser entendidas meramente como cambios del "peronismo desde arriba". Deben ser leídas también como una respuesta de aquél a los cambios que se produjeron al interior de los sectores populares. Este aspecto es central para comprender la territorialización de sus prácticas políticas y productivas.

Las transformaciones sociales, económicas y políticas acontecidas desde la década del setenta -y profundizadas en los noventa- se reflejaron en la territorialización de los sectores populares. La desocupación, la pérdida de centralidad de los ámbitos tradicionales de socialización, en general y política en particular, mostraron la relevancia del escenario barrial como ámbito de inscripción territorial y centro de las redes de sociabilidad y organización colectiva entre los habitantes de los barrios populares. Lejos de ser un mero lugar de residencia, el barrio se convierte en el espacio por excelencia de construcción de las identidades sociales y base de la acción colectiva (Merklen, 2005).
6 Desagregando las protestas sindicales por sector de actividad es posible reconocer, además, el contraste que se produce entre las acciones de protesta de los sindicatos de la educación, administración pública y servicios frente a las del sector industrial. Este último muestra, desde principios de la década del noventa, una proporción menor a la de los demás sectores así como también una disminución de la cantidad de protestas en las que participó. Esto nos permite ver, entonces, no sólo el decrecimiento del protagonismo sindical en la movilización social sino además que la reorientación de la fuerza de la capacidad de movilización, según la rama de actividad, se vincula con el impacto de las transformaciones económicas de más amplio alcance y sobre las que nos hemos referido anteriormente. (GEPSAC, 2006: 36-41)

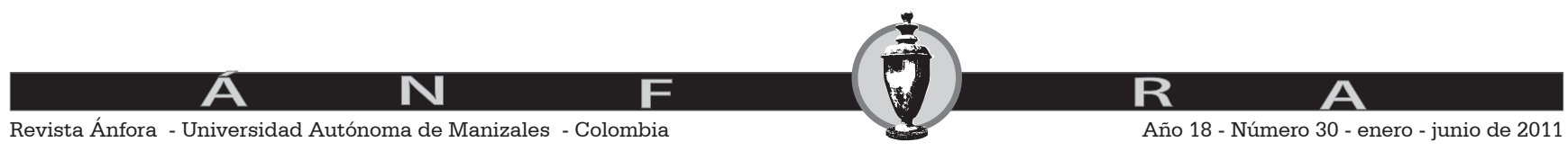


De esta forma, fue gestándose un tipo de existencia social con diferencias sustanciales en relación con el modelo liberal de ciudadanía, que expresaba una modalidad de existencia política. Este aspecto novedoso se convierte en sumamente necesario para entender la democracia, puesto que no deja de ser un medio para expresar y comunicarse con el sistema político.

De acuerdo con las ideas presentadas, para pensar la política en los sectores populares, y entre las y los jóvenes en particular, debemos tener en cuenta al menos dos significados en disputa. Por un lado, el que surge como producto de las transformaciones del peronismo y la creación de redes clientelares de contención social "desde arriba". Por otro, el que se conforma a partir de espacios de resistencia en los que se disputa aquel sentido y la política adquiere otras dimensiones a partir de experiencias organizativas situadas en los barrios. En la creación de estos proyectos colectivos se pone en juego el sentido del cambio social deseado, el cual, sin duda, tiene diversos significados.

En esta ponencia reflexionamos a partir de seis aspectos que nos permiten trazar un mapa y caracterizar las formas de compromiso y protagonismo de las y los jóvenes, especialmente, aquellos que están organizados políticamente.

\section{Seis puntos para entender la política y la militancia territorial en los barrios populares.}

UNO: entre la militancia político-social y la político-partidaria. El lugar de las redes sociales como soporte de la politización de las prácticas sociales y cotidianas.

La territorialización de la política se produce a partir de redes sociales previas de base comunitaria. De algunas de nuestras investigaciones ${ }^{7}$ se desprende que estas redes capilares tienen la capacidad de ser difusas y concentradas. Es decir, que son invisibles en muchos momentos y se hacen visibles y concentradas en ciertas coyunturas específicas, por ejemplo, en ciclos de movilización social ${ }^{8}$.

Las organizaciones territoriales pueden pensarse, entonces, como aglutinadoras de estas redes sociales preexistentes. Concentración y visibilización que sirve, a su vez, de base para la conformación de nuevas redes sociales. En otras palabras, que son capaces de potenciar las redes preexistentes.

Las redes más significativas para comprender las expresiones políticas de las y los jóvenes en los barrios populares bonaerenses son de diverso tipo: de vecindad, de parentesco, de origen (entre quienes provienen de otras provin-
7 Para profundizar ver Vázquez (2008 y 2009), Vommaro (2006 y 2008) y Vázquez y Vommaro (2008).

8 Esta característica la hace en un punto inasible, inaprensible, tanto para el poder "externo" (estatal en sus diferentes niveles), como para quienes estamos indagando acerca de ella en el presente.

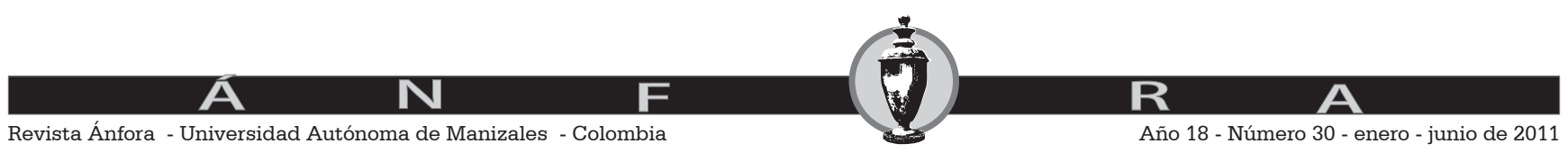


cias o de países limítrofes), de filiación política o militancia previa, vinculadas a la fe religiosa, vinculadas a consumos musicales, aficiones futbolísticas, formas de vestir, estéticas, formas de ejercer la sexualidad, entre las otras. Todas éstas deben ser contempladas en el proceso de constitución de prácticas políticas por parte de las y los jóvenes, puesto que son relevantes para entender las atribuciones de sentido sobre la política.

En este proceso de territorialización y politización de los lazos sociales locales y cotidianos, fueron múltiples los colectivos donde los y las jóvenes fueron protagonistas. Entre éstos, cabe mencionar especialmente los grupos de alfabetización, los bachilleratos populares ${ }^{9}$, las murgas ${ }^{10}$, los movimientos de desocupados, grupos de arte popular y callejero, medios de comunicación alternativos, entre otros. Las especificidades y aspectos comunes entre las diferentes experiencias tienen que ver con el tipo de definiciones políticas que fueron gestando.

Se trata de grupos pequeños en los que priman las relaciones cara a cara, construidos a partir de la revalorización del territorio como escenario pero también como objeto de las prácticas. En estos agrupamientos la autonomía ha sido un aspecto constitutivo de sus definiciones y prácticas político-ideológicas y se proclama no sólo respecto de las tradicionales formas organizativas sino, además, del protagonismo de los adultos en aquellos espacios.

La territorialización de la política supone, además, la creación de formas políticas o de militancias de nuevo tipo. Esto es, modalidades de militancia político-social y que se presentan como alternativas a la lógica político-partidaria y que está más ligada a lo estatal ${ }^{11}$. Antes que el reemplazo de una por otra, debemos reconocer las relaciones de tensión, conflicto y contradicción entre estas dos lógicas políticas, que, además, se agudiza en aquellas coyunturas de activación o visibilización de las prácticas territoriales.

Deteniéndonos un instante en este punto, podemos volver sobre un elemento que mencionamos anteriormente en cuanto a la constitución de las lógicas político social y otra político partidaria. Podemos ver cómo entre ellas existen múltiples relaciones de tensión e inclusive de contradicción.

La militancia político-social supone una forma de organización en la que tiene importancia central el territorio y lo comunitario, puesto que se trata de una práctica en la que la política y los asuntos cotidianos están entremezclados. En otras palabras, donde las múltiples dimensiones de la vida se politizan e involucran un abanico de cuestiones que van desde la música hasta el cuerpo y la intimidad. Esta política desde lo cotidiano, que podríamos también analizar como una politización de lo que antes era considerado social o reproductivo, puede ser analizada a partir de las propuestas de Badiou (1996 y 2000) quien aporta a la distinción entre lo estatal y lo político en el mundo actual, posibilitando la comprensión del componente político de las organizaciones sociales territoriales.

Esta politización también se asienta sobre la transformación de cuestiones
9 Los bachilleratos populares son espacios de educación y formación que se han constituido junto a diversas organizaciones sociales por parte de diferentes grupos -en general juveniles- en la Ciudad de Buenos Aires y las zonas suburbanas. Utilizan las metodologías de la educación popular y están orientados a posibilitar que las personas que no pudieron hacerlo, completen sus estudios secundarios, además de impulsar otras prácticas de formación alternativas a las que ofrece el sistema educativo oficial.

10 Se denominan murgas a los grupos de música callejera que se organizan -generalmentepara los carnavales pero que funcionan como ámbito de sociabilidad y encuentro a lo largo de todo el año. Estas agrupaciones están compuestas en gran parte por jóvenes y combinan música, baile y canto, con vestimentas y estandartes que identifican y distinguen a cada grupo.

11 Mientras la militancia político-social se expresa en las organizaciones sociales, en gran parte de base territorial y comunitaria; la militancia políticopartidaria se relaciona con instituciones ligadas a la disputa de poder en el Estado (ej. partidos políticos y sindicatos) y muchas veces a la participación en instituciones estatales. Si la delegación y la representación caracterizan a este último tipo de militancia, la político-social está más vinculada a la participación directa. Para ampliar este punto ver Vommaro (2006 y 2008).

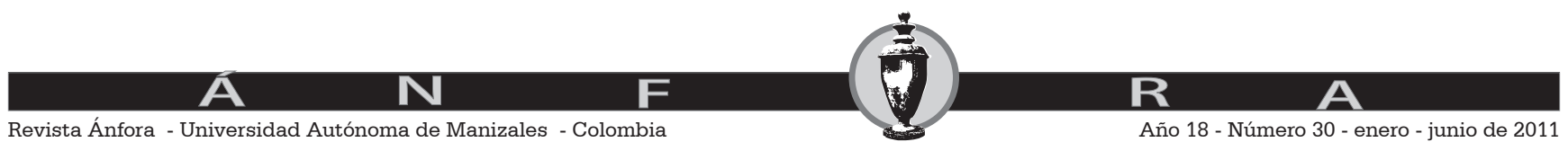


que anteriormente eran consideradas como constitutivas del ámbito privado y que pasan a ser problemáticas de carácter público, esto es, que merecen ser tratadas en ámbitos comunes. Esto se puede observar, como veremos más adelante, en el rechazo público a la persecución individualizada de la policía y se expresa públicamente en diferentes dimensiones estéticas y culturales como la música, el baile o la canción. La frontera difusa entre lo público y lo privado también muestra un contrapunto con la política partidaria tradicional.

En estos procesos de politización territorialmente situados, podemos identificar tres elementos importantes. En primer lugar, las formas organizativas, definidas por la búsqueda de modalidades organizativas y de toma de decisiones que se enfocan en la práctica de un tipo de democracia más participativa y directa. Más allá de sus diferentes resultados, se intenta problematizar y cuestionar la idea de delegación y representación. Esto último explica la preponderancia de la acción directa, la creación de tiempos y espacios propios y la dinámica asamblearia. En segundo lugar, las formas políticas que instituyen una politicidad de lo social que configura una militancia político-social alternativa y alterativa de la político-estatal. Por úlitmo, los procesos de subjetivación que se constituyen a partir de redes sociales comunes y ancladas comunitariamente, que configuran experiencias políticas autoafirmativas.

DOS: el territorio como construcción política y la política como construcción territorial.

La importancia del componente territorial en la política contemporánea puede abordarse a partir de las transformaciones del sistema capitalista y de los procesos productivos en la Argentina y el mundo en los últimos años. En este plano podemos reconocer la manera en que confluyen dos espacios anteriormente separados: el de producción (la fábrica) y el de reproducción (el barrio). El lugar de la producción y el de la reproducción se superponen y esto impacta en las diversas esferas de la vida social. Tiempo y espacio del trabajo confluyen y se articulan con el tiempo y el espacio de la vida cotidiana.

Por otra parte, el territorio no se presenta como algo preconstituido o previo, sino como un espacio a producir y que va construyéndose a medida que se gestan diversos procesos político-organizativos.

Es en esta doble dimensión local donde los y las jóvenes de los barrios populares del Gran Buenos Aires despliegan su vida cotidiana. Así, el territorio es un elemento de identificación y pertenencia ${ }^{12}$. Además, se desarrolla una reformulación entre lo local y lo global, constituyendo un territorio mixto, complejo, en el cual los significados locales se globalizan y los sentidos globales se localizan (Reguillo, 1997: 35).

Es en el territorio donde se despliegan los mecanismos de construcción de
12 Es necesario aclarar que estas formas de vinculación juvenil surgidas desde lo territorial se cruzan con otras modalidades que lo desbordan, como las redes construidas a partir de gustos musicales, estéticas o aficiones futbolísticas. Estas últimas se constituyen a partir de las tecnologías de la información y la comunicación disponibles que funcionan como "redes de producción-reproduccióncirculación y reconocimiento de sentidos y significados" (Reguillo, 1997:39).

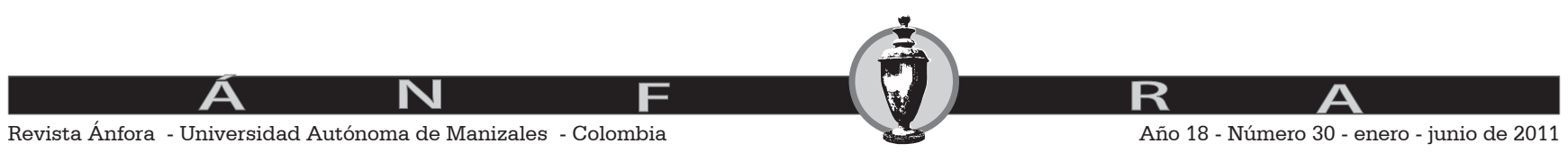


una identidad común, donde se vuelve posible potenciar lo múltiple y lo diverso sin que esto suponga la reproducción de la desigualdad. Tanto organizaciones sociales territoriales como colectivos culturales, experiencias educativas, medios de comunicación alternativos y grupos artísticos se han mostrado como espacios capaces de expresar y contener la diversidad que caracteriza a la juventud, transformándola en potencia colectiva.

La construcción de comunidad permite, así, que la diversidad que caracteriza al territorio y a los y las jóvenes, que las diferentes situaciones individuales y que la violencia capilar que domina la vida barrial juvenil se transformen en capacidad creadora al organizarse en un proyecto colectivo y comunitario. $\mathrm{Si}$ el poder (el Estado, el capital) separa, diferencia, clasifica, divide las redes sociales que posibilitan las prácticas políticas territoriales de los y las jóvenes se proponen reunir, integrar, componer, igualar. La alegría y lo afectivo desempeñan un rol importante en estos procesos, como retomaremos más adelante.

TRES: lógica estatal y autogestión. Los significados de la política en disputa.

Consideraremos ahora las maneras en las que las prácticas políticas de los y las jóvenes en los barrios populares se relacionan con el Estado. Podemos mencionar tres tipos de vínculo.

Uno de tipo asistencial, que se establece a partir de la asignación y el manejo de recursos materiales por parte del gobierno nacional, provincial y municipal. Sobre este vínculo se vuelven fundamentales las diferencias entre los y las jóvenes organizados y quienes no lo están. Esto es, entre quienes perciben recursos y asistencia estatal como parte de un colectivo y quienes lo hacen individualmente. Los grupos con recursos estatales logran, en parte, subvertir la idea misma de "asistencia" reinterpretando la recepción de recursos en un lenguaje de derechos y como producto de la misma organización colectiva, que les permite confrontar (y dialogar) con aquél. Quienes perciben ayuda individualmente, por el contrario, se convierten en la más clara expresión de la estigmatización, puesto que la ayuda aparece como compensación a una situación de marginalidad que esa persona parece encarnar como "jefe" o "jefa de hogar", como "madre soltera", como "joven desocupado", etc. Por otra parte, al concretarse la ayuda individualmente, se construye un espacio potencialmente colonizado por punteros políticos que funcionan como mediaciones político-institucionales en el plano barrial ${ }^{13}$. Es decir, que la lógica asistencialista puede devenir en una de tipo clientelar, y que definiremos a continuación.

También podemos referirnos sobre un vínculo de tipo represivo, que se manifiesta en la vida cotidiana de los y las jóvenes de sectores populares y que se profundiza en la relación de estos últimos con ciertas acciones contestatarias o de lucha, especialmente cuando éstas involucran formas de acción directa.
13 Con el nombre de "punteros" se conoce a dirigentes locales del Partido Justicialista con estrechos vínculos con el gobierno municipal, que se convierten en figuras claves, tanto en el control de los conflictos cotidianos del barrio como en los momentos electorales. Por otra parte, las "manzaneras" son delegadas de manzana que gestionan diferentes planes sociales en el Gran Buenos Aires. $\mathrm{Si}$ bien su origen se remonta a los procesos de tomas de tierras y asentamientos de los años ochenta, su existencia se institucionalizó cuando el entonces gobernador de la Provincia de Buenos Aires Eduardo Duhalde les asignó responsabilidad en la implementación de la asistencia social directa. Para ampliar, ver Merklen (2005: 59 y 87).

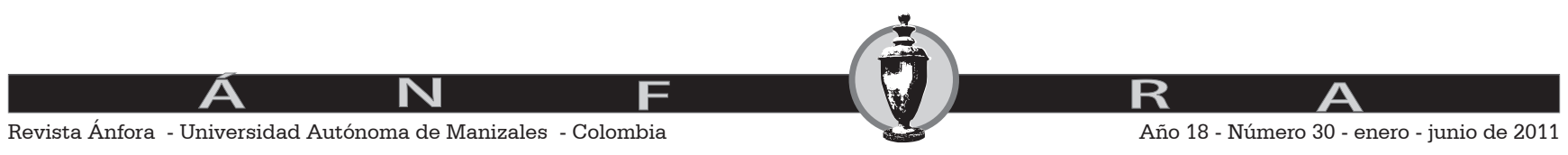


No podemos dejar de mencionar el proceso de judicialización de la pobreza y de la protesta social.

Por último, el que podemos denominar de tipo más clientelar, que plantean las redes asistenciales de los municipios que actúan a través del control territorial de los punteros del Partido Justicialista y que apuntan a reprimir o cooptar a los grupos barriales que se constituyan en una amenaza potencial o actual a sus intereses.

Los tres tipos de vínculos que mencionamos pueden cruzarse con tres modalidades de relación entre el Estado y las diferentes organizaciones políticas barriales. Éstas son: la negociación, el enfrentamiento y la autonomía. Estas modalidades atraviesan transversalmente cada práctica. Pueden confluir en una misma acción o puede haber momentos en que una prevalezca sobre las otras dos.

De lo dicho podemos también avanzar en la identificación de dos dinámicas, entre las cuales despliegan en el territorio las prácticas juveniles, en general, y las prácticas políticas de la juventud en particular: la de la autoafirmación y la del enfrentamiento. Si bien analíticamente podemos distinguir ambas lógicas, ligar la primera con la construcción territorial, comunitaria, autónoma y alternativa, y la segunda con la interlocución especular y la oposición simétrica al Estado; las dos están presentes -conflictivamente- en la construcción de las experiencias político-sociales. Sin embargo, muchas veces lo autoafirmativo tiende a primar ya que las dinámicas que se proponen son más alternativas que confrontativas respecto del poder dominante. Por otra parte, las dos dinámicas se integran como expresión del antagonismo social situado territorialmente.

De esta manera, las demandas de recursos y reconocimiento al Estado se entrelazan con momentos de práctica autoafirmativa. Así, los colectivos juveniles instituyen espacios de funcionamiento autónomo respecto del Estado -y también de los partidos políticos, los sindicatos o la Iglesia-que, no por tener a la autonomía como un horizonte de construcción política, dejan de recibir recursos materiales o simbólicos del Estado. Las murgas y los bachilleratos populares son dos ejemplos de esta compleja relación de demandas al Estado (generalmente ligadas con el pedido de recursos, pero también de reconocimiento, muy necesario y solicitado en el segundo caso) y ejercicio de la autogestión, en general acompañada por formas participativas de funcionamiento interno.

Una dimensión importante de la disputa entre las formas de la política juvenil en los barrios y el Estado es la apropiación y el uso del espacio público. Este conflicto tiene su base, tanto en el proceso de territorialización que describimos, como en el aumento de las prácticas basadas en la acción directa, que analizaremos más adelante. Generalmente, se expresa a través de enfrentamientos con la policía y la intervención del Poder Judicial y la autoridad municipal.

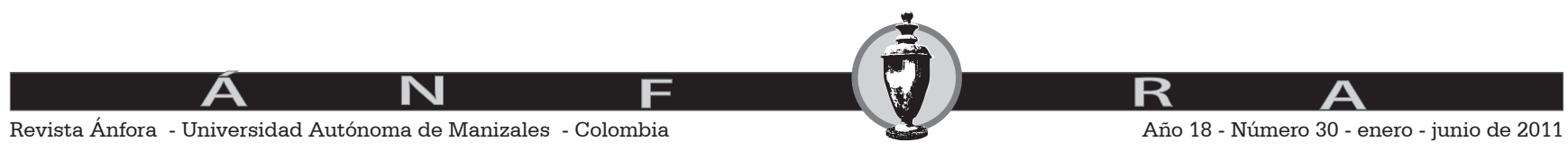


Desde las disputas producidas entre los y las jóvenes y la policía por habitar las esquinas bonaerenses, hasta los enfrentamientos en los cortes de ruta o acampes, pasando por los conflictos que surgen ante los recitales de música en los barrios (generalmente de rock, heavy metal o hip hop) y la actuación de las murgas en los carnavales, las tensiones generadas por el uso del espacio público a nivel local son recurrentes.

En la introducción mencionamos cómo la territorialización de los sectores populares aparecía como elemento central para comprender, tanto los significados de la política como las modalidades organizativas de los primeros.

Ahora bien, es posible hacer alusión no sólo a las nuevas organizaciones territoriales que derivan de este proceso, sino también a cómo éstas han sido capaces de generar nuevos territorios (organizacionales) no enmarcados en las prácticas territoriales cristalizadas por la operatoria de redes políticas clientelares. El ejemplo más significativo tal vez sea la participación que han tenido los y las jóvenes en las tomas de tierras y construcción de asentamientos urbanos que se han impulsado en diferentes barrios populares desde la década del ochenta, aún en épocas de la última dictadura militar ${ }^{14}$.

Sin embargo, otras formas de organización colectiva también reflejan la recreación del territorio a partir de las estrategias organizativas comunes. Podemos mencionar, por ejemplo, la creación de nuevos ámbitos productivos en los que se ha promovido la re-apropiación del espacio social a partir de premisas como la autogestión y la creación de relaciones más horizontales entre los trabajadores. En una palabra, la posibilidad de engendrar nuevos espacios políticos que cuestionan con su práctica cotidiana el tipo de inserción del Estado en el plano local. Como sugieren Delamata y Armesto (2005), son "actividades básicas y reivindicativas que transformaban el habitus asistencialista en relaciones de ayuda mutua y/o reclamos de derechos, mediante diferentes estrategias de redimensionamiento de la acción social: desde la transformación de cuestiones privadas en problemas compartidos o comunitarios, pasando por la politización de la dominación 'clientelar', hasta el desplazamiento de las reivindicaciones y reclamos hacia el Estado Nacional. Dependiendo del peso relativo que ocupe cada uno de estos ejes en la vida interna de la organización y en su articulación, nos encontraremos con nuevos territorios 'organizacionales' distintos".

La interrelación entre aspectos sociales y políticos puede ser entendida, entonces, como una de las características más relevantes de los procesos organizativos de la juventud de sectores populares. Es decir, la posibilidad de postular concepciones de la política que no sólo no están escindidas de las necesidades materiales cotidianas de los sujetos sino que, además, permiten politizar las demandas reivindicativas.

Las ideas presentadas permiten reconocer cómo para los y las jóvenes de los sectores populares el ámbito territorial no necesariamente debe ser vivido como espacio de "reclusión" y "marginalidad". Es decir, que la acción política
14 Para ampliar este punto ver Vommaro (2006) y Marchetti y Vommaro (2007).

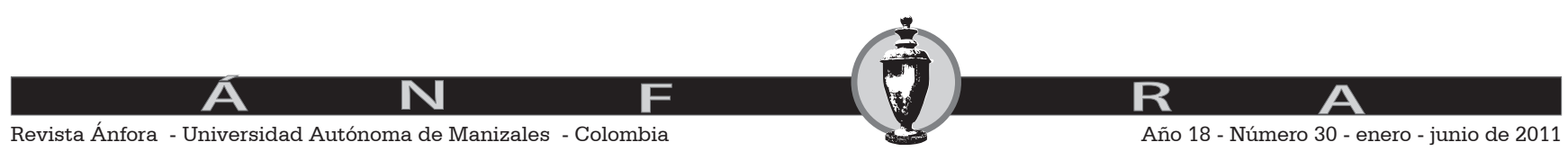


permite reconvertir los espacios haciendo de los barrios ya no un mero recinto de exclusión social, sino además, escenario de resistencia y contestación por parte de los y las jóvenes. Acordamos con Reguillo (2000) cuando afirma que "los actores juveniles, al inventar territorios para la acción en una forma de respuesta a las exclusiones, valores, símbolos y formas de comunicación derivadas de la globalización y portadoras de sus propios mecanismos de dominación, señalan que todos estos procesos de escala planetaria no desaparecen en el territorio, ni lo convierten en un 'no lugar', a la manera de Augé" (2000:146).

CUATRO: la política como ámbito de inscripción del antagonismo con la policía.

El aspecto sobre el que proponemos reflexionar aquí tal vez sea el de más importancia para comprender el lugar de la juventud en las experiencias organizativas barriales. Como mencionamos, éstas son múltiples y diversas, sin embargo, los discursos de interpelación dirigidos a los y las jóvenes constituyen uno de los aspectos comunes entre ellas. En diversos espacios (como talleres de murga, de arte, de oficios, movimientos de desocupados) y en un repertorio de formatos de protesta (tomas de tierras, ocupaciones, cortes de rutas o calles, etc.), los y las jóvenes se vuelven protagonistas.

Parte de los cambios en la política que narramos al principio permiten comprender por qué los y las jóvenes participan de estos ámbitos, mientras que su participación se retrae en los ámbitos tradicionales del régimen político democrático-liberal: menos participación en elecciones y retracción del compromiso en partidos políticos y sindicatos.

La desconfianza hacia las instituciones se desplaza en el ámbito territorial en la desconfianza hacia la policía. Para muchos y muchas jóvenes el barrio se convierte prácticamente en el único ámbito posible de socialización y de sociabilidad. Es por esto que su vínculo con las instituciones del Estado resulta restringido y, en muchos casos, únicamente se hace presente a partir de la presencia de punteros políticos y de la policía. Además, esta última se visibiliza a partir de las prácticas de hostigamiento y persecución permanente a los y las jóvenes. La criminalización de la juventud se hace particularmente evidente en los sectores populares, a lo que se suma la discriminación por su pertenencia social o su lugar de residencia.

Si las diferentes formas de organización colectiva reconocen particularidades, es posible identificar como hilo conductor entre ellas la manera en que permiten canalizar el rechazo hacia la policía ${ }^{15}$. Esto posibilita la construcción interpretativa de aquélla a partir de la posibilidad de reconocerla como antagonista, es decir, de politizar este vínculo.

Reflexionando en torno a uno de los formatos de protesta más novedosos en la Argentina en la última década -los cortes de ruta- podemos ver cómo
15 Los estudios acerca de los consumos culturales entre los jóvenes de sectores populares han mostrado la relevancia que poseen los estilos musicales y las identidades construidas en torno a aquellos para expresar las formas de ver y sentir al mundo. Como sostiene Zibechi (2003) este fenómeno puede ser considerado una "novedad" para los sectores populares, por cuanto "rompe con una tradición (en la que hubo muy escasas excepciones) de que la música para consumo de los sectores populares fuera elaborada por músicos de clase media" (2003:69). Las especificidades de esas estructuras de sentimiento propias de los jóvenes de sectores populares se han evidenciado a partir de la creciente relevancia que fue cobrando el repudio a la policía y la utilización de narrativas y términos en los que se expresa el repudio hacia el tipo de prácticas que éstos desarrollan en los barrios populares.

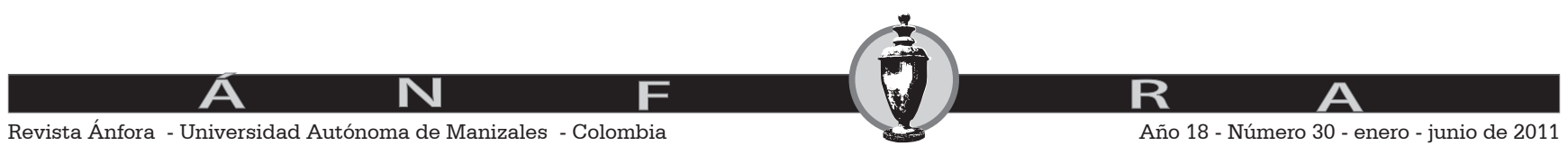


es marcada la presencia de los y las jóvenes en el área de seguridad de los mismos. Éstos buscan deliberadamente formar parte de la "seguridad" y participan frecuentemente en la primera fila o cordón del piquete, enfrentados directamente con la policía. En el dibujo a continuación, realizado por un joven referente de un movimiento de desocupados, se puede reconocer la disposición de los cuerpos en función del sentido que se da a la confrontación.

El dibujo fue realizado por Darío Santillán y se lo puede encontrar en: http:// www.prensadefrente.org/pdfb2/index.php/fot/2005/09/21/p508

De esta forma, "la participación en los piquetes subvierte esa relación de sometimiento individualizado, generando un espacio de reconocimiento donde confrontación e integración al colectivo se conjugan (...) el sentido de pertenencia a este colectivo permite expresar el rechazo y el antagonismo con la policía y los punteros de un modo que resulta imposible desde la individualidad en la vida cotidiana de los barrios populares" (Pérez, García y Vázquez, 2007: 36-37).

De ahí la importancia que cobran, no sólo la socialización de los y las jóvenes en los movimientos y organizaciones de las que forman parte, sino además, y fundamentalmente, las estrategias de confrontación que éstas llevan a cabo. La acción directa, como ya vimos y profundizaremos en el próximo punto, es el escenario de una producción identitaria central, a partir de la cual resulta posible identificar y reconocer en la policía un adversario político.

CINCO: acción directa y participación en el espacio público.

Una de las características de la movilización social en la Argentina desde mediados de la década del noventa ha sido la creación o innovación en el repertorio de las protestas sociales. Entre las acciones que innovaron el repertorio de movilización anterior podemos mencionar los cortes -de rutas, calles y vías-, la muestra artística, la olla popular, el acampe, el cacerolazo, el escrache, la ciberprotesta, el basurazo, la cadena humana y el corte de teléfonos. Durante y a partir de la década del noventa es posible reconocer una tendencia creciente de los denominados nuevos formatos de protesta que persiste a lo largo del tiempo (con algunos picos) y que es inversamente proporcional al decrecimiento de los formatos convencionales de protesta social, como la movilización, concentración, el lock out, el paro/huelga, la sentada, el motín, la ocupación, la huelga de hambre, entre otros (GEPSAC, 2006).

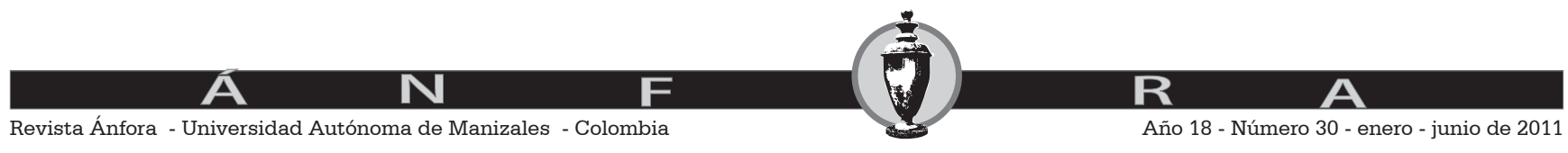


Viejos formatos de protesta

Nuevos formatos de protesta

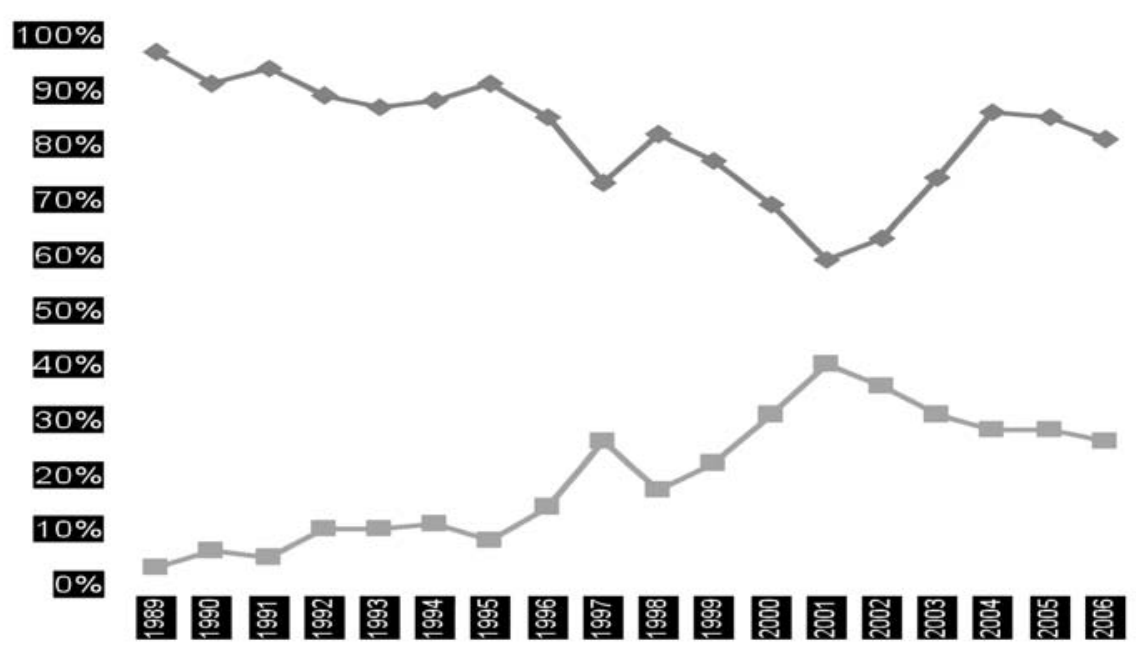

Total de protestas $(n=7263)$

Fuente: Base de protestas sociales del Grupo de Protesta Social y Acción Colectiva, Instituto de Investigaciones Gino Germani, Facultad de Ciencias Sociales, Universidad de Buenos Aires. 2006.

Contemplando nuestro interés por desentrañar los significados de la política entre los y las jóvenes, es relevante considerar la predilección que ellos han mostrado hacia los nuevos modos de adaptar su presencia en la escena pública.

Estos formatos de protesta social pueden ser analizados a partir de una característica común. Siguiendo a Pérez (2005), se trata de tipos de escenificación que ponen en juego una "política de los cuerpos". Esto puede ser leído en relación con un conjunto de elementos relevantes.

Primero, como expresión del carácter indelegable de la política o, en otras palabras, el cuestionamiento a la posibilidad de delegar en otro la representación del propio cuerpo y la propia voz. Por eso "poner el cuerpo" se convierte en sinónimo de participar. Es decir, para que la acción colectiva tenga lugar es preciso que se revele a través de la presencia física de sus manifestantes. En manos de sectores que han sido invisibilizados socialmente en tanto sujetos con capacidad de agencia política, como es el caso de los y las jóvenes de sectores populares, este tipo de protesta se vuelve fundamental puesto que no sólo permite enunciar reclamos sino además instituye formas de visibilidad social y la creación de identidades colectivas en el mismo accionar. Por eso, no sólo es relevante la visibilización de los cuerpos sino además y

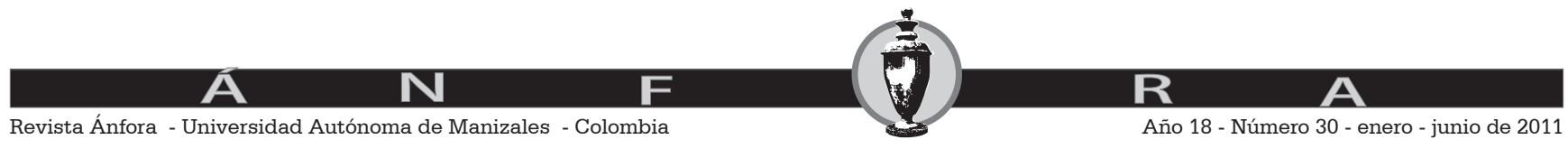


fundamentalmente, la "carnavalización de la protesta, la dramatización de los referentes identitarios, la imaginación para captar la atención de los medios de comunicación, trastoca las relaciones en el espacio público y señala la transformación en los modos de hacer política" (Reguillo 2000:148).

En segundo lugar, la creciente relevancia de las acciones directas en el nuevo repertorio de protesta social no hace sino poner en cuestión una idea que ha calado hondo en las ciencias sociales de las últimas décadas. Hacemos alusión a la idea de que la política se encuentra cada vez más mediatizada y virtualizada ${ }^{16}$.

En tercer término, consideramos que hay otra cuestión relevante para pensar la relación de los y las jóvenes con la política. Siguiendo a Vázquez (2008), no sólo los cuerpos posibilitan la creación de espacios de resistencia y visibilidad sino que, además, los cuerpos mismos de los y las jóvenes deben ser interpretados como ámbitos de inscripción de la resistencia, como una búsqueda por construir una hexis corporal alternativa a la del orden social hecho cuerpo. Así es como cobra relevancia el reconocimiento de una nueva estética creado en torno a la protesta social juvenil, en la que lo político y lo cultural se encuentran inevitablemente articulados.

\section{SEIS: la figura del militante "desclasado" en la política territorial"17.}

La política en los barrios populares pone en juego, también, la reflexión acerca del tipo de presencia que poseen jóvenes provenientes de sectores medios que se han vinculado con diferentes experiencias organizativas territoriales.

Las singularidades de este tipo de presencia pueden ser aprehendidas a partir de dos afluentes. Por un lado, la figura del joven militante "desclasado" puede ser analizada a partir de la creciente pauperización de las condiciones de vida ya no solamente de los sectores populares sino de las clases medias. De esta forma, como propone Zibechi (2003), es posible reconocer la existencia de nuevos pobres jóvenes que comparten las situaciones de precariedad y desocupación con los integrantes de los sectores populares pero que, al mismo tiempo, dominan herramientas que son en gran parte, proporcionadas por su educación formal, y que no existían en aquel sector social. Estas herramientas se articulan con colectivos de base territorial que permiten potenciar capacidades organizativas.

Por otro lado, la figura del joven "desclasado" puede ser estudiada a partir de un conjunto de jóvenes externos a los barrios populares que han arribado a los mismos a partir de trayectorias de militancia política anteriores. Es decir, cuya militancia es reorientada a partir de la revalorización de las prácticas ancladas territorial y barrialmente como escenario del activismo. La presencia de activistas externos a los barrios pero con una militancia de base, ha sido fundamental en un conjunto de espacios de resistencia protagonizados por los y las jóvenes que se fueron gestando al calor de la profundización del neoliberalismo en la Argentina.
16 De esto último se desprende también uno de los argumentos que hemos trabajado más arriba en cuanto a la importancia que posee la presencia de los punteros en los barrios como respuesta a la territorialización de los sectores populares. Como también la de aquellas figuras que encarnan a la política estatal en el plano local y que tan necesarias se vuelven para entender los entramados y las disputas políticas en los barrios. Estas presencias no dejan de ser complejas puesto que, más allá de la búsqueda por diferentes colectivos por combatir sus formas clientelares, también son interpretadas como una forma de presencia del Estado, una suerte de reaseguro contra la exclusión y la posibilidad -aunque sea simbólica- de reconocerse como parte de una comunidad política.

17 Este apartado retoma algunas de las conclusiones de la tesis de maestría "La socialización política de jóvenes piqueteros. Un estudio a partir de las organizaciones autónomas del conurbano bonaerense" realizado por Melina Vázquez.

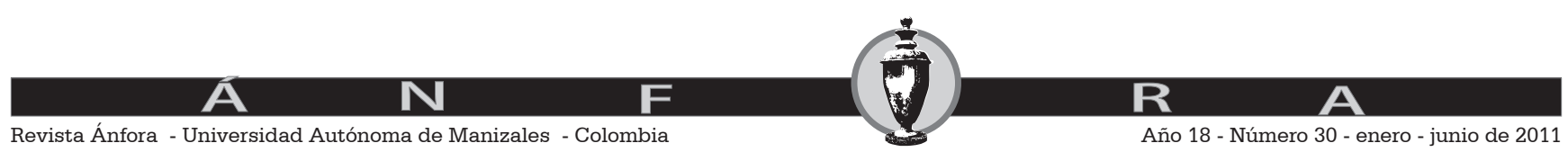


De este segundo afluente de militantes nos interesa remarcar dos aspectos sumamente interesantes. En primer lugar, los y las jóvenes no sólo reivindican la militancia en el territorio sino que además, en muchos casos, remarcan la importancia de vivir en el territorio donde se milita, en los casos en que lo anterior se traduce en una mudanza al barrio, narrada a través de la idea del desclasamiento.

En segundo lugar, lo anterior nos permite reflexionar acerca de las relaciones entre estas modalidades de compromiso político y las de la militancia revolucionaria de las décadas del sesenta y del setenta. A primera vista no deja de ser relevante el modo en que se interpreta la idea misma del desclasamiento. En el marco de la militancia revolucionaria, desclasarse suponía proletarizarse, o sea, romper con la clase social de pertenencia, sumarse a las filas de la clase obrera y promover espacios de resistencia desde la militancia en las fábricas. Es decir, vivir, trabajar y luchar como un obrero. Ahora bien, para estos y estas jóvenes, por el contrario, el desclasamiento expresa su conversión en vecinos o habitantes del espacio territorial donde la militancia tiene lugar. Podemos ver así cómo la militancia no parece susceptible de ser inscripta en el paradigma clásico de la producción, sino en el ámbito barrial. Esto parece corroborar que la hipótesis acerca de la territorialización de la política está vinculada también al proceso de territorialización de la producción, que mencionamos brevemente más arriba. Además, se hace evidente no sólo la importancia que cobra la idea de "convertirse" en vecino para poder militar en un barrio, sino además cómo -tal como se desprende del discurso de estos jóvenes-el trabajo formal no aparece como escenario posible de la politización. Esto se relaciona con la inexistencia de algún tipo de identidad construida en torno a la figura del trabajador asalariado o industrial o una cultura política construida en torno al espacio laboral como ámbito central del compromiso político y la politización de las prácticas. Para los y las jóvenes "desclasados" es su identidad como "luchadores" - no como "trabajadores"aquella que da sentido a su experiencia personal y colectiva.

Lo anterior es sumamente significativo para pensar acerca de cómo el espacio de trabajo industrial y salarial deja de ser postulado como ámbito de la militancia política por excelencia, al mismo tiempo que lo territorial se convierte en el centro de la experiencia social ligada al militantismo.

\section{Consideraciones finales. La construcción de formas políticas alternativas entre las y los jóvenes: ¿nuevos caminos hacia el cambio social?}

$\mathrm{Al}$ analizar las formas en las que se expresa la política protagonizada por jóvenes en los barrios populares de la Argentina, discutimos una idea que ha sido bastante difundida y que asocia "lo juvenil" con el desencanto y la apatía. Para quienes sostienen esto, la crisis de la política clásica repercutió especialmente

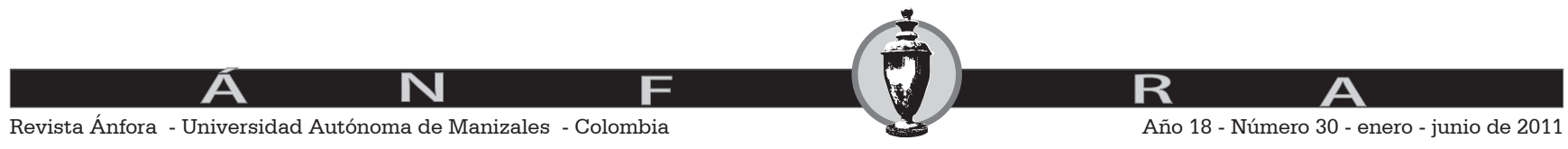


entre los y las jóvenes y generó ausencia de todo tipo de organización y acción colectiva. Desde esta óptica, la crisis de la política institucional expresaría, al mismo tiempo, la crisis de la participación política juvenil.

Siguiendo a Pierre Rosanvallon (2007), consideramos que es preciso relativizar o interpretar cuidadosamente el significado que le atribuimos a la desconfianza sobre las instituciones democráticas. Para eso, nos advierte el autor, es preciso ejercitar un tipo de reflexión más abierta que nos permita comprender los cambios en la participación política. En sus palabras, "La ciencia política se ha esforzado durante mucho tiempo por distinguir formas de 'participación no convencional', constatando que se multiplican, aunque la concurrencia a las urnas pueda parecer menos frecuente. Los indicadores de participación en huelgas o manifestaciones, la firma de petitorios, la expresión de formas de solidaridad colectivas en las situaciones extremas sugieren así que no hemos ingresado en una nueva era de apatía política y que la idea de un creciente repliegue sobre la esfera privada no tiene fundamento. De modo que conviene más hablar de mutación que de declinación" (2007:35-6).

A partir de lo anterior, podemos dar cuenta al mismo tiempo, del modo en que se produce el alejamiento de los y las jóvenes de las instituciones y prácticas de lo que denominamos militancia político-partidaria, a partir de la disminución de la participación en espacios como partidos o sindicatos, así como del alejamiento y la desconfianza hacia las instituciones y actividades convencionales de implicación en la esfera pública. También, del modo en que se produce la transformación de los espacios en los que los y las jóvenes se sienten más interpelados a participar. En otras palabras, reconocer que la politización se inscribe en canales alternativos a las vías institucionales y estatales de la política. De este modo, se vuelve relevante analizar los procesos de subjetivación entre las generaciones de jóvenes como emergentes de un proceso histórico determinado -como el descrito- antes que como una característica inherente a la condición juvenil, ya sea en su versión romántica (que parte de la "predisposición" a la acción colectiva) o en la idea del desencanto hacia la política como condición sine qua non de la juventud.

En este artículo, entonces, mostramos que es posible observar entre los y las jóvenes de los barrios populares bonaerenses un desplazamiento de las formas tradicionales de organización y participación política hacia otro tipo de espacios y prácticas en los que no sólo no rechazan la política en cuanto tal, sino que muchas veces es la misma impugnación de los mecanismos delegativos de participación y toma de decisiones aquello que politiza sus experiencias. De este modo, se constituyen nuevas subjetividades políticas a partir de la oposición a las anteriores modalidades de participación en el régimen político democrático liberal: las elecciones y la representación corporativa a partir de la vinculación con partidos y sindicatos. (Vázquez, 2007).

No obstante, pensamos que las singularidades de los espacios organizativos entre los y las jóvenes que analizamos en este trabajo, son difíciles de reconocer desde otros enfoques. Es decir, que no solamente son problemáticos

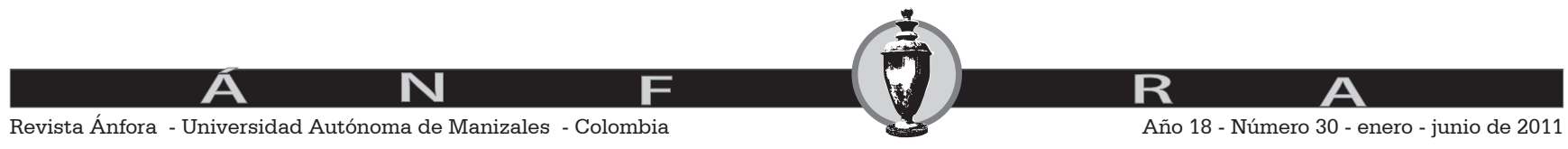


en aquellos que persisten en analizar los ámbitos tradicionales de la política, siendo allí donde más evidente se vuelve el repliegue de la participación entre los y las jóvenes, sino además, nos alejamos de la mirada característica de aquella izquierda partidaria que acota el carácter transformador de las prácticas al imaginario revolucionario clásico. Desde esta matriz resulta complejo reconocer en colectivos de base territorial posibles espacios de politización, como también reconocer la politicidad de sus demandas y de las cuestiones cotidianas que se problematizan en la experiencia colectiva.

Como decía Pierre Bourdieu (2002) en su clásico trabajo "La 'juventud' no es más que una palabra", las disputas entre generaciones aparecen como producto de aspiraciones construidas en etapas diferentes, donde aspectos que para una generación pueden haber resultado de una lucha a lo largo de toda la vida, otra generación los recibe, sin más, al nacer. Sin duda, es de esa forma como entendemos la relación con las instituciones democráticas por parte de las generaciones que han vivido en tiempos de dictadura y aquellas otras que han nacido en la transición o en plena democracia. De ahí la dificultad que ha suscitado entre muchos investigadores repensar los sentidos de la política entre los y las jóvenes, tomando como materia las especificidades y características que presentan en lo concreto, más allá de categorías preconcebidas para otros escenarios, modalidades y épocas.

Para terminar, podemos decir que si bien entre los cientistas sociales de América Latina en los últimos años han buscado recuperar y no desestimar el potencial político de las prácticas asociativas entre los y las jóvenes, el desafío actual consiste en repensar cómo estas prácticas políticas territoriales pueden aportar a un proceso de transformación social más amplio que contenga -y al mismo tiempo supere- lo local, sin que por eso deba quedar encorsetado en los sentidos clásicos del cambio social.

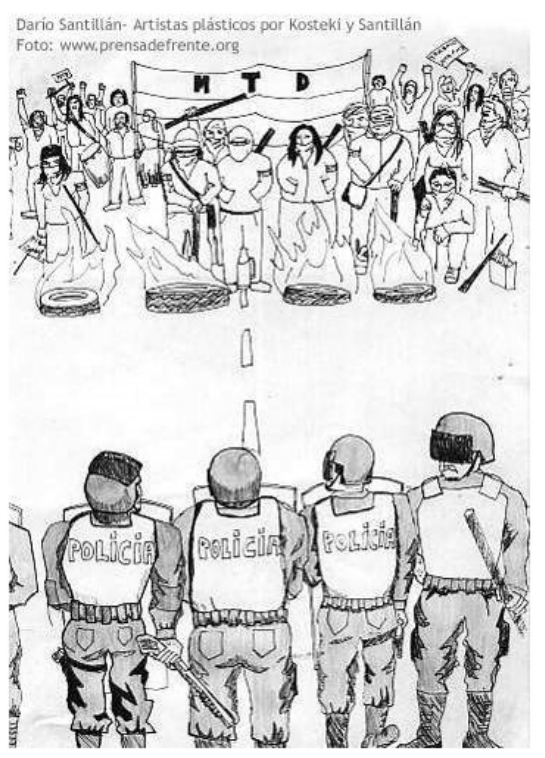

Dibujo realizado por Darío Santillán. Se lo puede encontrar en: http:// www.prensadefrente. org/pdfb2/index.php/ $\underline{\text { fot } / 2005 / 09 / 21 / \mathrm{p} 508}$

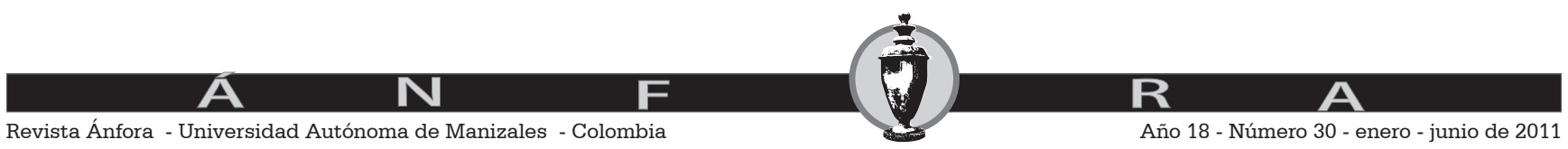




\section{Bibliografía}

Aboy Carlés, Gerardo (2001). Las dos fronteras de la democracia argentina: la reformulación de las identidades políticas de Alfonsín a Menem. Buenos Aires, Homo Sapiens.

Auyero, Javier (1993). Otra vez en la vía. Notas e interrogantes sobre la juventud de sectores populares. Buenos Aires, Espacio Editorial.

Badiou, Alain (1996). "Política, partido, representación y sufragio", en Revista Acontecimiento, $\mathrm{N}^{\circ}$ 12, Buenos Aires.

Badiou, Alain (2000). Movimiento social y representación política. Buenos Aires, IEF-CTA.

Bourdieu, Pierre (2002) "La 'juventud' no es más que una palabra" en Sociología y cultura. México, Grijalbo.

Braslavsky, C. (1986). La juventud argentina: Informe de situación. Buenos Aires, Centro Editor de América Latina.

CONADEP (1984). Nunca Más. Buenos Aires, Eudeba.

Delamata, Gabriela (2004). Los barrios desbordados. Las organizaciones de desocupados del Gran Buenos Aires. Buenos Aires, Eudeba.

Delamata, Gabriela y Armesto, Melchor (2005). "Construyendo pluralismo territorial. Las organizaciones de desocupados del Gran Buenos Aires en la perspectiva de sus bases sociales". En Delamata (comp.) Ciudadanía y territorio. Buenos Aires, Espacio.

Feixa, Carlés (1998). De jóvenes, bandas y tribus. Ariel, Barcelona.

Frederic, Sabina (2003) Buenos vecinos, malos políticos: moralidad, política y política en el Gran Buenos Aires. Buenos Aires, Prometeo.

GEPSAC (2006). Transformaciones de la protesta social en la Argentina, 1989-2003. Buenos Aires: IIGG. Disponible en: http://www.iigg.fsoc.uba. ar/Publicaciones/DT/DT48.pdf.

Izaguirre, Inés (1992). Los desaparecidos. Recuperación de una identidad expropiada. Buenos Aires: IIGG. Disponible en: http://www.iigg.fsoc. uba.ar/conflictosocial/libros/izaguirre/losdesaparecidos/inesdesap_07. htm\#cuadro4.

Jelin, Elizabeth (1985) "Los movimientos sociales en la Argentina contemporánea: una introducción a su estudio" en Jelin, E.(comp.) Los nuevos movimientos sociales I. Mujeres. Rock nacional. Buenos Aires, Centro editor de América Latina.

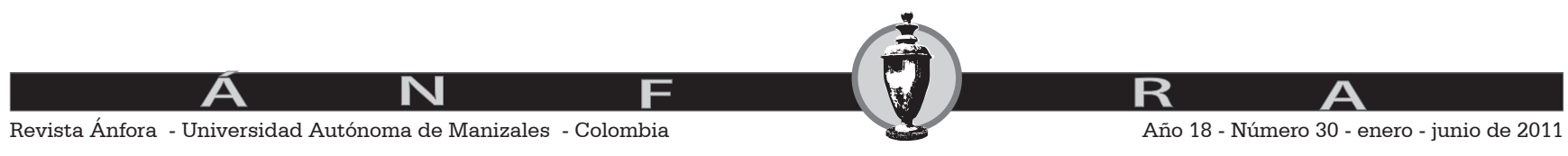


Margulis, Mario y Urresti, Marcelo (1998). "La construcción social de la condición de juventud". En Cubides, Humberto, Laverde Toscano, María Cristina y Valderrama, Carlos Eduardo. Viviendo a toda. Jóvenes, territorios culturales y nuevas sensibilidades. Bogotá, Fundación Universidad Central, Siglo del Hombre Editores.

Marchetti, Pablo y Vommaro, Pablo (2007). "Las tomas de tierras y asentamientos de 1981 en Solano: aproximaciones para el estudio de una experiencia de organización social en épocas de dictadura". En: Jornadas Interescuelas/Departamentos de Historia. (XI: 2005: Fac. de Filosofía y Letras. Univ. Nac. de Tucumán). Actas publicadas.

Merklen, Denis (2004). "Sobre la base territorial, la movilización popular y sobre sus huellas en la acción". En Lavoratorio, Año 6, Nro 16, 46-53.

Merklen, Denis (2005). Pobres ciudadanos. Buenos Aires, Gorla.

Palermo, Vicente (1999) “¿Mejorar para empeorar?: la dinámica política de las reformas estructurales argentinas". En: Torre, Juan Carlos (et. al.). Entre el abismo y la ilusión: peronismo, democracia y mercado. Buenos Aires, Norma.

Pérez, Germán (2005) "Pálido Fuego: Hannah Arendt y la declinación de la figura del trabajador en las sociedades contemporáneas. Apuntes sobre los piqueteros en Argentina". En Schuster, Federico, Naishtat, Francisco, Nardacchione, Gabriel y Pereyra, Sebastián (Comps.). Tomar la palabra. Estudios sobre protesta social y acción colectiva en la Argentina contemporánea. Buenos Aires, Prometeo.

Pérez, Germán, García, Analía y Vázquez, Melina (2007). "Poner el cuerpo. Sobre los significados de la Masacre del Puente Pueyrredón". En: Revista Ciencias Sociales No 67, Buenos Aires, UBA.

Reguillo Cruz, Rossana (1997). "El oráculo en la ciudad, Creencias prácticas y geografías simbólicas. Una agenda comunicativa". En Revista Diálogos de la comunicación, Vol. 49. México, 33 - 42.

Reguillo Cruz, Rossana (2000). Emergencia de culturas juveniles. Estrategias del desencanto, Norma editorial, Colombia.

Rosanvallon, Pierre (2007). La contrademocracia. La política en la era de la desconfianza. Buenos Aires, Manantial.

Sidicaro, Ricardo (1998). "La gran mutación de los 90: crisis de los valores y el problema de los jóvenes". En: Sidicaro, Ricardo y Tenti Fanfani, Emilio (Comps.). La Argentina de los jóvenes. Entre la indiferencia y la indignación. Buenos Aires, UNICEF/Losada.

Vázquez, Melina (2008). "La socialización política de jóvenes piqueteros. Un estudio a partir de las organizaciones autónomas del conurbano bonaerense", tesis de maestría, Facultad de Ciencias Sociales, Universidad de Buenos Aires, mimeo.

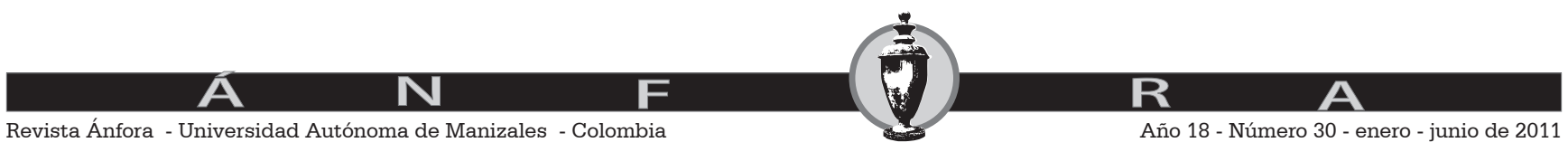


Vázquez, Melina (2009). "La política desde abajo: narrativas militantes de jóvenes desocupados en Argentina". En: Revista Latinoamericana de Ciencias Sociales Niñez y Juventud, Vol. 7, Nro. 1, Colombia.

Vommaro, Pablo. (2004). La producción y las subjetividades en los movimientos sociales de la Argentina contemporánea: el caso del MTD de Solano. Buenos Aires: CLACSO-Asdi. Disponible en: http:// bibliotecavirtual.clacso.org.ar/ar/libros/becas/2002/mov/vommaro.pdf

Vommaro, Pablo. (2006). "Acerca de una experiencia de organización social: las tomas de tierras y los asentamientos de 1981 en Solano". En: Revista de Historia Bonaerense. Año XIII, № 31. Diciembre de 2006. Instituto y Archivo Histórico Municipal de Morón.

Vommaro, Pablo. (2008). "El trabajo territorial y comunitario en las organizaciones de trabajadores desocupados: el caso del MTD de Solano". En Pereyra, Sebastián, Pérez Germán y Schuster, Federico (eds.) (2008). La huella piquetera. Avatares de las organizaciones de desocupados después de 2001. Buenos Aires, Al margen.

Zibechi, Raúl (1997). La revuelta juvenil de los noventa. Las redes sociales en la gestación de una cultura alternativa. Montevideo, Nordan.

Zibechi, Raúl (2003). Genealogía de la Revuelta. Argentina: sociedad en movimiento. Montevideo, Nordan.

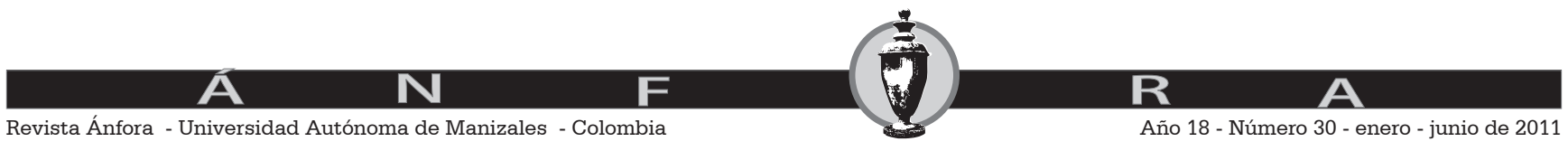

